\title{
Laparoscopy training in Belgium: results from a nationwide survey, in urology, gynecology, and general surgery residents
}

This article was published in the following Dove Press journal:

Advances in Medical Education and Practice

30 January 2015

Number of times this article has been viewed

\author{
Gunter De Win ${ }^{1,2}$ \\ Wouter Everaerts 3,4 \\ Dirk De Ridder ${ }^{3}$ \\ Griet Peeraer ${ }^{2}$ \\ 'Department of Urology, University \\ Hospital Antwerp, ${ }^{2}$ Faculty of \\ Medicine, University of Antwerp, \\ Antwerp, Belgium; ${ }^{3}$ Department \\ of Development and Regeneration, \\ KU Leuven, Leuven, Belgium; \\ ${ }^{4}$ Department of Urology, Royal \\ Melbourne Hospital, Melbourne, VIC, \\ Australia
}

Background: The purpose of this study was to investigate the exposure of Belgian residents in urology, general surgery, and gynecology to laparoscopic surgery and to training of laparoscopic skills in dedicated training facilities.

Methods: Three similar specialty-specific questionnaires were used to interrogate trainees in urology, general surgery, and gynecology about their exposure to laparoscopic procedures, their acquired laparoscopic experience, training patterns, training facilities, and motivation. Residents were contacted via their Belgian specialist training organization, using Survey Monkey as an online survey tool. Data were analyzed with descriptive statistics.

Results: The global response rate was $58 \%$. Only $28.8 \%$ of gynecology respondents, $26.9 \%$ of urology respondents, and $52.2 \%$ of general surgery respondents felt they would be able to perform laparoscopy once they had finished their training. A total $47 \%$ of urology respondents, $66.7 \%$ of general surgery respondents, and $69.2 \%$ of gynecology respondents had a surgical skills lab that included laparoscopy within their training hospital or university. Most training programs did not follow the current evidence about proficiency-based structured simulation training with deliberate practice.

Conclusion: Belgian resident training facilities for laparoscopic surgery should be optimized.

Keywords: simulation, questionnaire, resident education, minimal invasive surgery training, surgical case load, implementation of laparoscopy training

\section{Introduction}

For many gynecological, abdominal, and urological procedures, laparoscopy has replaced the open surgical approach. This minimally invasive technique offers many benefits to patients, in terms of cosmesis, postoperative pain, length of hospital stay, and return to daily activities.

The surgical competencies required to perform laparoscopic surgery are challenging and require surgical trainees go through an intensive learning period. ${ }^{1}$ Medicolegal regulations, increasing patient expectations, and time constraints imposed by the European Working Time Directive make it increasingly difficult for trainees to learn these complex procedures on patients in theater. Furthermore, feedback on surgical performance has an important impact on the learning curve but is not always easy during laparoscopic surgery in theater.

Therefore, numerous training methods have been developed to supplement patientrelated operating experience. Surgical simulation training in dedicated skills labs is one such method, which aims to teach trainees technical and nontechnical skills outside
Department of Urology, University Hospital, University of Antwerp, Wilrijkstraat 10, 2650 Edegem,

Antwerp, Belgium

Email gunterdewin@me.com 
operating theater without compromising patient safety. Simulation training offers a safe environment for practice and error, opportunities for feedback, and assessment and standardized experience for trainees. ${ }^{2}$ While simulation cannot completely replace clinical learning, the potential benefits of simulation training are widely recognized. Therefore, there is considerable interest in the implementation of surgical simulators in training programs as an adjunct to clinical learning. ${ }^{3}$

Training in a simulation lab has shown to dramatically improve residents' skills in the simulated environment. ${ }^{4}$ The ultimate goal of a simulation program is to show transferability of these lab-acquired skills to the clinical setting, meaning that improvements in clinical operative performance can be objectively quantified after simulation training. Training until proficiency, distributed training, and deliberate practice all have shown to be important factors to gain most benefit out of a simulation program. ${ }^{5-8}$ Repeated studies have shown that a well-designed simulation training program has significant impact on the clinical learning curve. ${ }^{9,10}$

This survey focused on the implementation of structured training in minimally invasive surgery in Belgium, in urology, general surgery, and gynecology, and evaluated whether the current training curricula are evidence-based.

\section{Material and methods}

\section{Questionnaire}

A previously validated questionnaire about the current state of minimally invasive surgery training for general surgery residents in Canada was adapted for Belgian residents. ${ }^{11,12}$ This questionnaire has also been used for similar purposes in the Netherlands. ${ }^{13}$ A few questions (eg, possibility for deliberate practice and training until proficiency) were added to check whether Belgian surgical education applies the current evidence-based principles about simulation training. Three similar questionnaires were developed for trainees in gynecology, general surgery, and urology. Only the questions about specialty-specific surgical procedures were different.

While Belgium has three official languages (Dutch, French, and German), all medical trainees are required to have a basic knowledge of English, and so the questionnaire was kept in its original language. Survey Monkey was used to design the questionnaire and gather data.

\section{Respondents}

Each specialty-specific questionnaire was presented to the specific specialty organization for residents: the European Society for Residents in Urology Belgium (ESRU.BE), the Belgian Association of Surgical Trainees (BAST), and the Flemish association for obstetrics and gynecology (Vlaamse Vereniging voor Obstetrie en Gynaecologie [VVOG]) for the Flemish (Dutch-speaking) gynecology trainees. There was no specific trainee organization for obstetrics and gynecology in Belgium.

As no specific ethical board existed for this kind of research, the questionnaire was discussed in detail within each trainee organization. None of the organizations had any ethical concerns. Residents were informed that they were not obliged to complete the questionnaire but that by filling in the survey, they gave consent to participation. They were assured that all data would be anonymized.

After agreement of ESRU.BE, BAST, and VVOG, each organization emailed the web link to the questionnaire to all its trainees. Together with this web link, an introduction to the questionnaire, informing the residents about the importance of the questionnaire for future training opportunities, was sent. Also, the concept of anonymity of the respondents was stated. Residents could only complete the questionnaire once because an internet protocol (IP)-lock was incorporated in the web link.

To maximize the response rate, two emails were sent with 2 months in between, and all the residents who completed the questionnaire could participate in a draw for an iPad mini.

The questionnaire addressed basic personal and practice demographics, laparoscopic training during residency, interest and performance of laparoscopy, laparoscopic simulation training, and factors influencing implementation of laparoscopy training in current residency. The complete questionnaire can be found in Supplementary material. For some questions, multiple answers were possible.

Data were reviewed and analyzed using standard descriptive statistics. Statistical analysis was performed using SPSS Statistics for Windows, Version 20.0 (IBM Corp, Armonk, NY, USA). Graphs were made with Prism 5 (GraphPad Software Inc., La Jolla, CA, USA).

\section{Results \\ Demographics}

The questionnaire was emailed to 315 trainees. The global response rate was 58\% (64\% for urology trainees, 67\% for general surgery trainees, and 51\% for gynecology trainees). Mean age of the respondents was 27.9 years for general surgery trainees, 29.1 years for urology trainees, and 27.5 years for gynecology trainees. Among the respondents, 63.5\%, $59.3 \%$, and $12.3 \%$ were males in urology, general surgery, and gynecology, respectively. A total $32 \%$ of urology trainees 
were involved in a $\mathrm{PhD}$ program compared with $7.7 \%$ of general surgery trainees and $8.2 \%$ of gynecology trainees. Figure 1 shows the distribution according to the year of training, and Figure 2 shows the distribution according to the different Belgian universities.

\section{Ready for practice}

Only $28.8 \%$ of gynecology respondents, $26.9 \%$ of urology respondents, and $52.2 \%$ of general surgery respondents felt they would be able to perform laparoscopic surgery once they had finished their training program. Most of them reported they would need an extra laparoscopic fellowship once their residency was finished, to be able to perform advanced laparoscopic surgery $(95.5 \%, 88 \%, 91 \%$ for gynecology, urology, and general surgery, respectively).

When taking a detailed look at the respondents who had laparoscopy in their career plan, only $16.7 \%$ felt prepared to perform laparoscopic procedures. In correspondence, $83.3 \%$ of them indicated they would need an extra fellowship to be able to perform advanced laparoscopic procedures.

When asked whether they were ready for general practice within their specialization once their training program was finished, $50 \%$ of gynecology residents, $52 \%$ of urology residents, and $38 \%$ of general surgery residents gave a positive answer (Figure 3).

\section{Skill labs}

In all, $48 \%$ of urology respondents, $66.7 \%$ of general surgery respondents, and $69.2 \%$ of gynecology residents stated they had access to a laparoscopic skills lab in their training hospital or university. Surprisingly, they did not get to use that skills lab very often (Figure 4).

A total $47 \%$ of the urology trainees, $36.7 \%$ of general surgery, and $70.5 \%$ of gynecology trainees who only had the possibility of getting skills lab training reported that

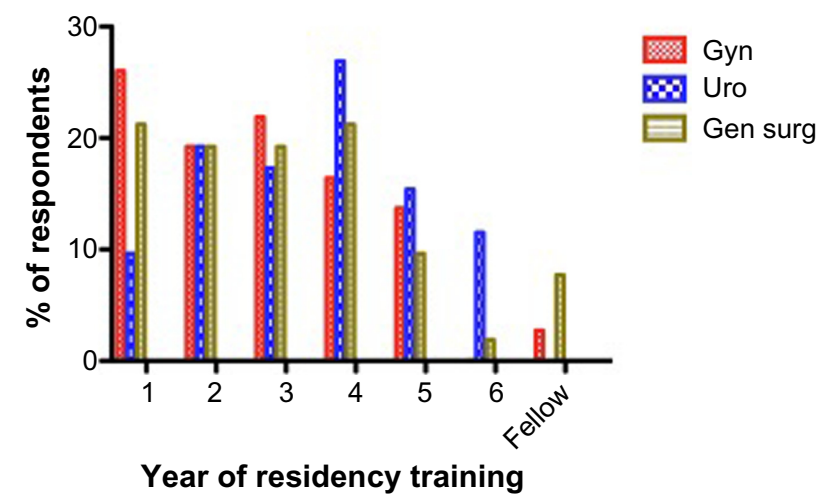

Figure I Percentage of respondents over the different training years. Abbreviations: Gen surg, general surgery; Gyn, gynecology; Uro, urology.

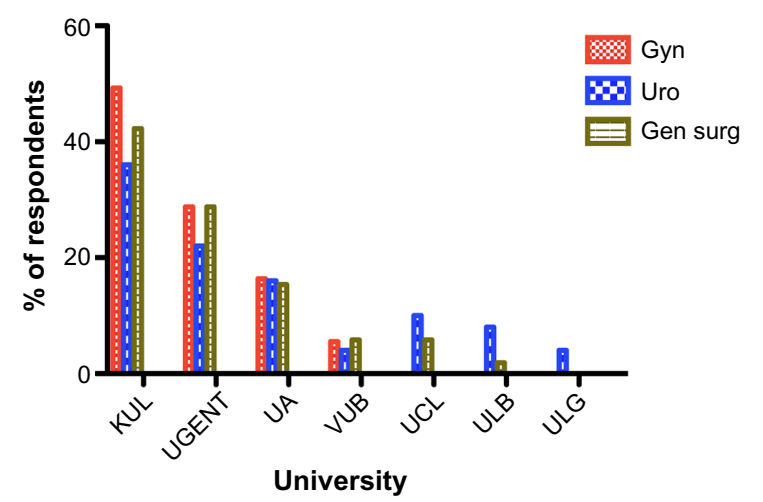

Figure 2 Distribution of respondents across the different Belgian universities. Abbreviations: Gen surg, general surgery; Gyn, gynecology; Uro, urology; KUL, Catholic University of Leuven; UA, University of Antwerp; UCL, Université Catholique de Louvain; UGENT, Free University Ghent; ULB, Université Libre de Bruxelles; ULG, Université de Liège; VUB, Free University of Brussels.

their performances were measured during training. In most cases, "time to complete an exercise" was the only performance measurement, except for gynecology trainees, among whom $5.5 \%$ reported the use of a procedure-specific score. A total $15 \%$ of urology trainees, $10.7 \%$ of general surgery trainees, and $37.2 \%$ of gynecology trainees had to reach a certain proficiency score on these exercises, but for none of the trainees was it necessary to reach a proficiency score to be able to perform laparoscopy in theater.

For most trainees, the duration of the skills labs was more than 1.5 hours, even up to a full day. Only a minority had training sessions between 30 minutes to 1.5 hours (Figure 5). The distribution of exposure to different types of exercises for different specialties is shown in Figure 6.

Most respondents $(56.3 \%$ for general surgery, $50 \%$ for gynecology, $57.6 \%$ for urology) did not have any laparoscopy training before their residency started. About one-third of respondents (35.4\% for general surgery, 31.3\% for gynecology, and $33.3 \%$ for urology) had a short introduction course. Only a very small minority had a full course of several days

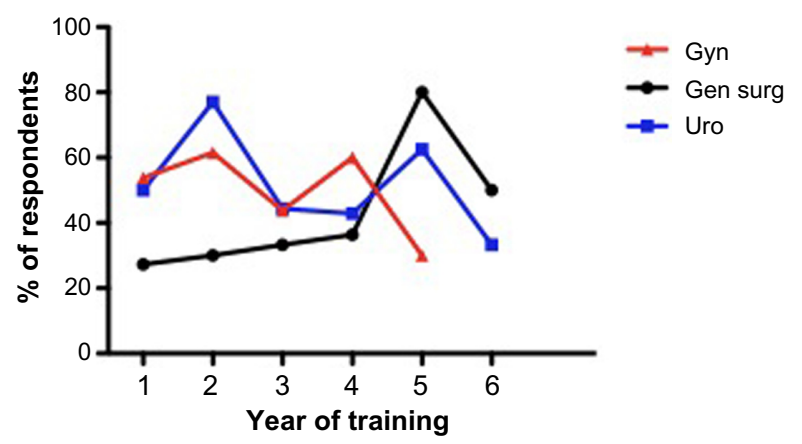

Figure 3 Ready for general practice within their specialty at the end of their residency.

Abbreviations: Gen surg, general surgery; Gyn, gynecology; Uro, urology. 


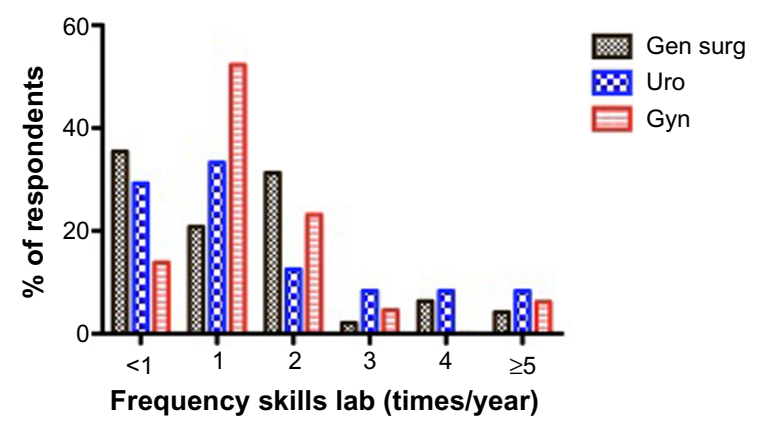

Figure 4 Frequency of skills labs per year.

Abbreviations: Gen surg, general surgery; Gyn, gynecology; Uro, urology.

with examination, but this in the context of a scientific study about laparoscopy training and simulation.

Nearly all trainees (except $5 \%$ of general surgery trainees) said that laparoscopic skills lab training was rather important or very important for their future career. Nearly all respondents said that the laparoscopic skills training they received was rather helpful or very helpful for their performance in the operating room (OR). For $5 \%$ of general surgery trainees and $2.3 \%$ of urology trainees, it made no difference.

Only $26 \%$ of urology respondents, $28.8 \%$ of general surgery respondents, and $38.4 \%$ of gynecology respondents had the possibility of performing deliberate practice in their skills lab. However, of those who had the possibility of performing deliberate practice, the majority did not use that possibility very often (Figure 7). The reasons mentioned for not going to the practice lab more often were (in order): lacking time to go to the lab, not enough exercises available, unpractical opening hours, or unpractical location.

In all, $26 \%$ of gynecology residents, $36 \%$ of general surgery residents, and $52 \%$ of urology residents received extra laparoscopy training not organized by their training program

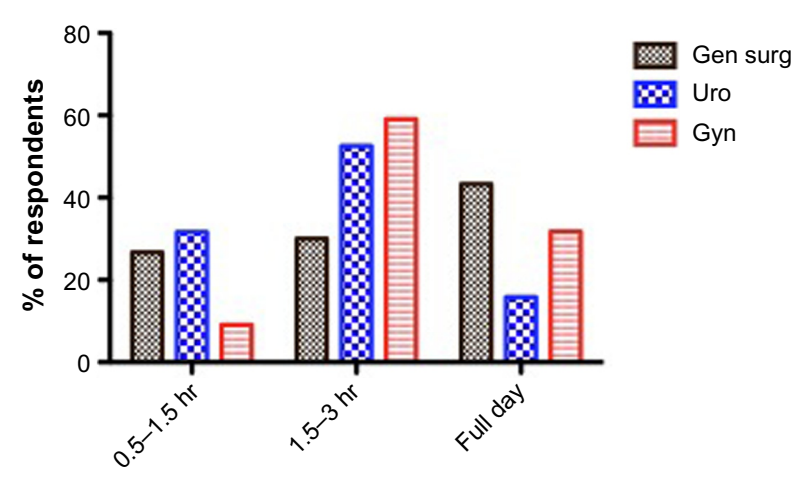

\section{Duration of laparoscopic skills labs}

Figure 5 Duration of skills labs. Abbreviations: Gen surg, general surgery; Gyn, gynecology; hr, hours; Uro, urology.

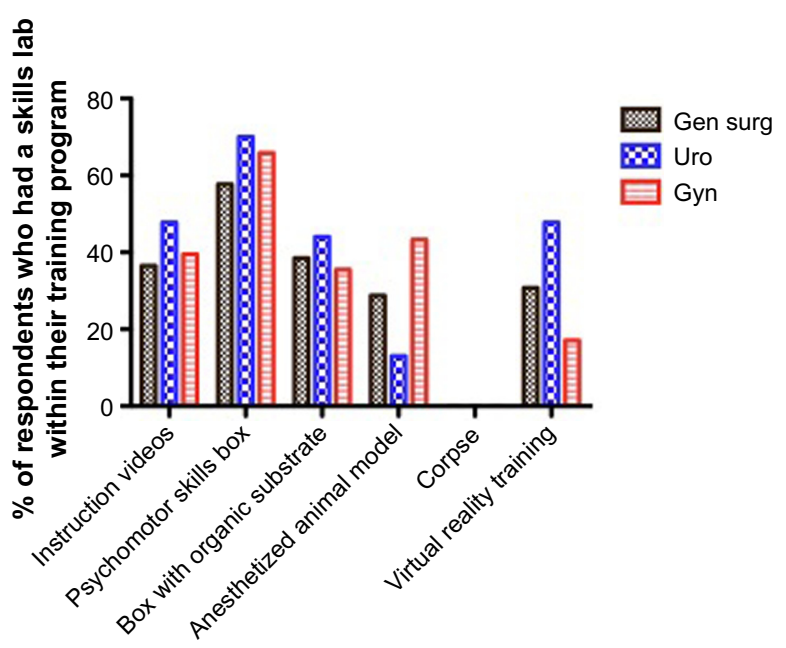

Figure 6 Types of exercises.

Abbreviations: Gen surg, general surgery; Gyn, gynecology; Uro, urology.

or university. All of the respondents who followed such an extracurricular course said this course was very helpful.

For all gynecology residents who followed an extracurricular course, this course was paid by the trainee $\mathrm{him} /$ herself, while for urology registrants, the course was paid for by industry or organized by the ESRU.BE and funded by industry. For all general surgery trainees, this extracurricular course was paid for by industry. Most extracurricular courses took place at the Research Institute against Digestive Cancer (Institut de Recherche Contre les Cancers de l'Appareil Digestif [IRCAD])/ European Institute of TeleSurgery (EITS) in Strasbourg, France and were paid by industry (for 54\% of urology trainees and $55.6 \%$ of general surgery trainees). None of the gynecology trainees followed a course in IRCAD. Some other mentioned centers were the International Centre for Endoscopic Surgery (Centre International de

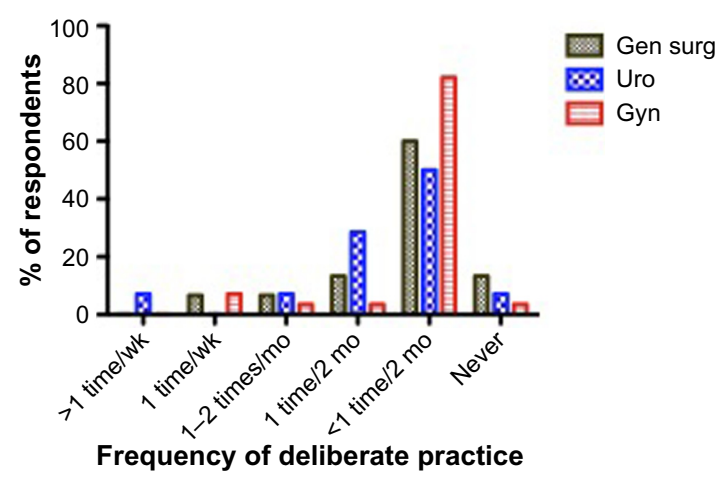

Figure 7 Frequency of deliberate practice for those who had the possibility of performing deliberate practice.

Abbreviations: Gen surg, general surgery; Gyn, gynecology; mo, month; Uro, urology; wk, week. 
Chirurgie Endoscopique [CICE]) in Clermont-Ferrand France and the Endoscopic Training Centre Antwerp (ETCA) or Rotterdam Training Center, each named by two respondents. A total $28 \%$ of general surgery respondents took an extra course, paid for by industry, at the Centre for Surgical Technologies - KU Leuven. For $80 \%$ of gynecology trainees who took an extra course, this was also at the Centre for Surgical Technologies - KU Leuven.

None of the gynecology trainees, but $13.5 \%$ (seven) of urology trainees and $5.8 \%$ of general surgery trainees (three) said they had a personal training box at home; four of them never used this box, three of them did once a month, one did once a week, and the others did less than once every 2 months. Five of these seven students reported they did not use this home box more often because they did not have time; three of them said the camera quality was poor; three of them said that the instruments were poor; and one said there were not enough exercises available.

\section{Training possibilities in the OR}

For basic laparoscopic procedures among general surgery trainees during their first 3 years of training, nearly all trainees reported to have performed less than 25 laparoscopic appendectomies and less than 25 cholecystectomies. One third-year trainee had performed between 51 and 100 laparoscopic appendectomies and between 101 and 125 cholecystectomies. All fifth- and sixth-year trainees had performed more than 25 laparoscopic appendectomies and more than 25 lap cholecystectomies, and all of them felt comfortable performing these procedures on their own. A total 50\% performed more than 100 laparoscopic cholecystectomies, and 50\% performed less than 50 .

Only $20.5 \%$ of urology trainees, $28.8 \%$ of general surgery trainees, and $25.9 \%$ of gynecology trainees reported

Table I Why did residents not get the chance to perform advanced laparoscopic cases?

\begin{tabular}{|c|c|c|c|}
\hline \multirow[t]{2}{*}{ Factors affecting MIS } & \multicolumn{3}{|c|}{ Mode $^{a}$} \\
\hline & URO & GYN & SURG \\
\hline Lack of resident interest & I & I & I \\
\hline Lack of attending surgeons interest & 2 & 3 & 3 \\
\hline Limited number of cases & 4 & 2 & 2 \\
\hline Limited chance to act as primary surgeon & 5 & 5 & 4 \\
\hline Lack of OR time & 4 & 4 & 4 \\
\hline Lack of surgical support & 2 & 3 & 3 \\
\hline Resident's lack of laparoscopic skills & 2 & 3 & 2 \\
\hline Supervisor's lack of laparoscopic skills & I & 3 & 1 \\
\hline
\end{tabular}

Note: ${ }^{\mathrm{O}} \mathrm{On}$ a scale of $\mathrm{I}-5$, where $\mathrm{I}=$ not concerned, and $5=$ very concerned.

Abbreviations: GYN, gynecology; MIS, minimally invasive surgery; OR, operating room; SURG, surgery; URO, urology. there were enough training opportunities to learn advanced laparoscopy during their training. On a Likert scale between 1 and 5, they could point out the reason why they thought they had not learned enough advanced laparoscopy in theater. The summary is found in Table 1 . Table 2 summarizes advanced laparoscopic case experience at the end of the fifth and sixth training year (and fourth and fifth training year for gynecology), and Table 3 shows which procedures residents believed they would be able to perform competently upon completion of their residency.

\section{Discussion}

Based on this survey, it is clear that laparoscopy training in Belgium should be improved.

Although a general response rate of $58 \%$ is not very high, respondents were evenly distributed across the different disciplines, years of training, and training university according to the Belgian situation. The VVOG sent the web link to their student members and recently graduated consultants, who were not allowed to complete the questionnaire, while the ESRU.BE and BAST, as resident organizations, only contacted the trainees. This incorrectly lowered the global response rate. For general surgery, the response rate $(67 \%)$ was much better than for a previous questionnaire study in the same study population $(26 \%) .{ }^{14}$ For all these reasons, the current cohort is a very representative sample of urology, gynecology, and general surgery trainees in Belgium.

The vast majority of respondents are exposed to laparoscopic procedures although only a minority have the possibility to perform advanced laparoscopic procedures. As a result, most residents did not feel they would be comfortable to perform laparoscopic procedures by the end of their training. For gynecology trainees and general surgery trainees, residents were certain they would be able to perform basic laparoscopic procedures (diagnostic laparoscopy, tubal sterilization, appendectomy, and cholecystectomy). Compared with a similar study for general surgery residents in Belgium, in the current study, all finalyear trainees performed more laparoscopic appendectomies and cholecystectomies, and all performed "enough" of both procedures, as was deemed necessary in that previous study. ${ }^{14}$ However, also in the current study, most of the trainees did not have enough exposure to advanced laparoscopic cases. In urology, there are no basic laparoscopic procedures performed and an extensive learning curve for advanced procedures was reported. ${ }^{15}$ Moreover, this translates into a lower urology cohort that felt able to perform urological laparoscopy at the end of their residency. 
Table 2 (Advanced) laparoscopic case experience at the end of the fifth and sixth training year (fourth and fifth for gynecology)

\begin{tabular}{|c|c|c|c|c|c|}
\hline Procedures & No cases & I case & 2-4 cases & $5-10$ cases & $>10$ cases \\
\hline Nephrectomy & $16.6 \%$ & $16.6 \%$ & $33.3 \%$ & $33.3 \%$ & $0 \%$ \\
\hline Partial nephrectomy & $100 \%$ & $0 \%$ & $0 \%$ & $0 \%$ & $0 \%$ \\
\hline Nephroureterectomy & $53.8 \%$ & $23 \%$ & $23 \%$ & $0 \%$ & $0 \%$ \\
\hline Pyeloplasty & $53.8 \%$ & $23 \%$ & $15.3 \%$ & $7 \%$ & $0 \%$ \\
\hline Radical prostatectomy & $76.9 \%$ & $0 \%$ & $23.1 \%$ & $0 \%$ & $0 \%$ \\
\hline Orchidopexy & $92.3 \%$ & $7.6 \%$ & $0 \%$ & $0 \%$ & $0 \%$ \\
\hline Prolapse & $46.1 \%$ & $7.6 \%$ & $23.0 \%$ & $15.3 \%$ & $7.6 \%$ \\
\hline Ventral hernia & $20 \%$ & $0 \%$ & $60 \%$ & $20 \%$ & $0 \%$ \\
\hline Right hemicol & $60 \%$ & $0 \%$ & $20 \%$ & $20 \%$ & $0 \%$ \\
\hline Inguinal hernia & $20 \%$ & $0 \%$ & $40 \%$ & $0 \%$ & $40 \%$ \\
\hline Bariatric & $40 \%$ & $0 \%$ & $20 \%$ & $0 \%$ & $40 \%$ \\
\hline Nissen fundoplication & $40 \%$ & $20 \%$ & $20 \%$ & $20 \%$ & $0 \%$ \\
\hline Sigmoid & $40 \%$ & $0 \%$ & $20 \%$ & $20 \%$ & $0 \%$ \\
\hline Rectal & $60 \%$ & $40 \%$ & $0 \%$ & $0 \%$ & $0 \%$ \\
\hline Diagnostic & $0 \%$ & $0 \%$ & $5.8 \%$ & $5.8 \%$ & $88.2 \%$ \\
\hline Tubular sterilization & $0 \%$ & $0 \%$ & $5.8 \%$ & $29.4 \%$ & $64 \%$ \\
\hline Ovarian cystectomy & $11.7 \%$ & $17.6 \%$ & $29.4 \%$ & $11.7 \%$ & $29.4 \%$ \\
\hline Hysterectomy & $17.6 \%$ & $0 \%$ & $17.6 \%$ & $35.2 \%$ & $29.4 \%$ \\
\hline Pelvic floor disorders & $64.7 \%$ & $11.7 \%$ & $5.8 \%$ & $0 \%$ & $5.8 \%$ \\
\hline
\end{tabular}

A recent pan-European survey for training of European urology residents in laparoscopy also showed a similar cohort of only $23 \%$ of residents who stated they would have satisfactory laparoscopy skills at the end of their

Table 3 Which of the following procedures will you be able to perform at the end of your training?

\begin{tabular}{ll}
\hline Procedure & $\%$ of correspondents \\
\hline Nephrectomy & $53.6 \%$ \\
Nephroureterectomy & $26.8 \%$ \\
Orchidopexy & 17.1 \\
Partial nephrectomy & $14.6 \%$ \\
Prolapse & $24.4 \%$ \\
Pyeloplasty & $39 \%$ \\
Radical prostatectomy & $17 \%$ \\
Adrenal & $10.8 \%$ \\
Bariatric & $45.9 \%$ \\
CBD exploration & $10.8 \%$ \\
Gastric jejunostomy & $32.4 \%$ \\
Gastric resection & $16.2 \%$ \\
Hepatic resection & $8.1 \%$ \\
Inguinal hernia & $67.5 \%$ \\
Nissen fundoplication & $29.7 \%$ \\
Pancreatectomy distal & $5.4 \%$ \\
Rectal & $16.2 \%$ \\
Right hemicol & $45.9 \%$ \\
Sigmoid & $29.7 \%$ \\
Splenectomy & $16.2 \%$ \\
Ventral hernia & $67.6 \%$ \\
Diagnostic & $94.5 \%$ \\
Endometriosis (mild to moderate) & $25.5 \%$ \\
Hysterectomy & $43.6 \%$ \\
Ovarian cystectomy & $56.4 \%$ \\
Pelvic floor disorders & $3.6 \%$ \\
Salpingectomy & $69.1 \%$ \\
Tubular sterilization & $90.9 \%$ \\
\hline Abbrevaton: CBD &
\end{tabular}

Abbreviation: $\mathrm{CBD}$, common bile duct. training. ${ }^{16}$ A recent basic laparoscopic skills evaluation for European urology residents showed that even the level of basic laparoscopic skills in final-year residents is low. ${ }^{17}$ In Canada, 33.9\% of final-year residents performed more than 20 laparoscopic nephrectomies, and 68\% performed more than ten. ${ }^{18}$ None of the final-year urology trainees in Belgium said they had performed more than ten laparoscopic nephrectomies. This is an enormous difference. Are there not enough cases available, or do urology trainees lack laparoscopic skills? Probably both, but it is clear that only urology residents responded that the limited number of available cases appeared to be an important factor for why those residents thought their training opportunities were affected. Although most final-year residents did not perform more than ten laparoscopic nephrectomies during their residency, more than $50 \%$ of all urology trainees (first to sixth year) believed they would be able to perform a laparoscopic nephrectomy at the end of their residency. This stands in sharp contrast with the reported learning curves and underscores the significant gap between what residents initially expect from their training, on the one hand, and the limited number of procedures they will in reality be able to perform independently during their training, on the other hand. For general surgery trainees, perceived "end of training" laparoscopic abilities for most procedures are comparable with their Canadian counterparts. Belgian trainees felt more comfortable with bariatric surgery (45.9\% vs 2.3\%), while Canadian trainees felt more comfortable with laparoscopic sigmoid surgery (29.7\% vs $52.3 \%) .{ }^{11}$ 
Lack of theater time is one of the most frequently mentioned reasons explaining why residents thought they did not have enough opportunities to learn advanced laparoscopy. A recent Irish study showed that after the introduction of the European Working Time Directive, the reduction of working hours was accompanied by a decline in operative experience during residency. ${ }^{20}$ Similar results were obtained in a previous British study. ${ }^{19}$ Also for gynecology trainees, there appears to be a lack of surgical training. ${ }^{21}$

The detrimental effects of lack of OR time can partially be overcome by offering laparoscopic simulation training. ${ }^{22}$ The purpose of training outside theater is to provide residents with all the necessary basic skills to enable a "jump start" in theater so that more time can be spend focusing on the surgical procedure itself rather than on basic skill acquisition to perform the procedure.

Our study shows that about two-thirds of the trainees in gynecology and general surgery had the possibility of attending a laparoscopic simulation course in a dedicated skills lab related to their training center. For urology residents, this was only $47.9 \%$. This is an enormous difference from a recent Canadian study, in which $85.7 \%$ of urology residents had access to a laparoscopic skills lab. ${ }^{18}$ All our respondents reported the courses had a positive impact on their performance in the OR and a positive influence on their future career. However, when critically evaluating these courses, most of these courses were poorly designed. Firstly, the vast majority had the possibility of training only once a year or less in the simulation lab. Secondly, training sessions lasted more than 1.5 to 3 hours or even a full day. Various studies have shown the positive impact of more frequent, distributed, and shorter training sessions, and the lack of retained skills during longer training sessions. ${ }^{5,22}$ Thirdly, only a minority of trainees had to reach a certain proficiency score during training, and none of them had to obtain a proficiency score to be allowed to perform laparoscopy in theater. Proficiency-based training is a necessary component of an evidence-based simulation curriculum. This training allows for variation between students in the amount of training time and number of practice trials needed, while keeping mastery constant. ${ }^{1}$ Stefanidis et al clearly showed that laparoscopic skill acquisition and transfer of simulation skills to the operating theater were better when those skills were learned in a proficiency-based training curriculum. ${ }^{7,23}$ Fourthly, only a very small minority had the possibility of performing deliberate practice. In addition, those who had access to deliberate training facilities report they rarely used that possibility due to lack of time, unpractical location, or lack of interest. This is a confirmation of earlier studies..$^{24,25}$

When a preclinical proficiency-based laparoscopy course is given to medical students with an interest in a surgical career, deliberate practice was done intensively. ${ }^{1}$ Furthermore, a preclinical proficiency-based course for medical students is easier to organize and has a positive impact on the real learning curve. ${ }^{26}$

Many urology and general surgery trainees had a simulation course at an expensive international training center, offered by a medical company. Unfortunately, none of the gynecology trainees had the same opportunity. However, gynecology trainees received more training in animal labs at their local training center. Although it is beneficial for residents that the lack of structured simulation training in their core training programs can be compensated by industryfunded training courses, this creates ethical dilemmas and limits a resident's independence. Also, the funding that industry is allowed to sponsor is diminishing. Furthermore, there is some controversy about the usefulness of short procedure-based courses taught by surgeons experienced in minimally invasive surgery. ${ }^{27}$

Based on our finding, we formulate a number of suggestions to improve simulation training in Belgium. Of course we agree that resident organizations, together with specialty organizations, organize and coordinate industry-sponsored courses. But on its own, this is definitely not sufficient. Current educational evidence has to translate to the implementation of more laparoscopic simulators in all training hospitals. In 1999, this was also one of the important suggestions in the previous survey; however, most training centers still do not offer this possibility to their trainees. ${ }^{14}$ Simulation boxes do not have to be expensive. Enough studies have shown that low-fidelity models are sufficient to acquire basic laparoscopic skills. ${ }^{28-30}$

Residents should also be encouraged to buy or construct a training system for training at home. Although our respondents who already had a training box at home were not that happy with their personal system, recent studies evaluated some promising examples. ${ }^{31-33}$ Further, performing deliberate distributed practice at home should be easier to fit into a resident's schedule.

Adequate and efficient feedback, together with a minimum requirement for practice time, obligatory assessment, and corresponding consequences, should be set in order to stimulate residents to practice at home. ${ }^{34}$ Moreover, proficiency scores should be communicated, and certification should be introduced. Residents should also be confronted 
with the results of surgical education research showing that only proficiency scores on the simulator correlate with improved clinical performance.

Surgical services are also increasingly organized into subspecialties. Subspecialty training and fellowships can be a good alternative for advanced laparoscopic procedures. A recent review showed the effectiveness of mentorship programs for advanced urological laparoscopy. Unfortunately, such programs are not widespread. ${ }^{35}$ Also for general surgery, procedures like adrenal surgery, splenectomy, hepatic and pancreatic resection, and rectal surgery may be better reserved for subspecialty fellows. This also means that Belgian subspecialty training programs have to be developed further.

A concerning finding is that only half of the respondents felt ready to go out into general practice. As shown in Figure 3, final-year trainees felt less prepared than did second-to-final-year trainees. It is possible that this has nothing to do with their available skills and knowledge, but more with being uncertain and afraid about upcoming responsibilities. A previous study also showed that the residents' perceived degree of skills was lower than that actually assessed by their senior tutors. ${ }^{36}$

Competency-based medical education with trustworthy professional activities and surgical portfolios will both help surgical trainers to identify those trainees who need more experience and will make trainees feel more comfortable about their gained experience. ${ }^{37}$

Recently, a simple model for teaching and assisting residents, to guide faculty and resident interaction in the OR, and designating a resident's earned level of autonomy for a given procedure, was developed. ${ }^{38}$ Also, use of procedurebased assessments, undertaken on a regular basis when an index procedure is performed, will be interesting. ${ }^{39}$ We propose these tools together with an online logbook or portfolio, to monitor resident's autonomy for different procedures and to find out how to optimize surgical training for each resident personally. This opens an area for further research. ${ }^{40}$

\section{Acknowledgments}

We express our great appreciation of the BAST, ESRU-BE, and VVOG, who agreed to collaborate and distributed the web link to the questionnaire to their residents. Special thanks to Pieter Uvin, François Legrand, Jan Bontinck, Lieven Depypere, and Marleen Parisis. Also, we thank all the residents who took the time to complete the questionnaire.

\section{Author contributions}

GDW selected and updated the survey questions, analyzed the data, and wrote the manuscript. WE helped optimize the questionnaire and revised the article critically for important intellectual content. DDR made substantial contributions to the conception of the study, helped perform the data analysis, and revised the article critically for important intellectual content. GP designed the online survey, helped gather all the data, and revised the article critically for important intellectual content. All authors gave final approval of the manuscript.

\section{Disclosure}

DDR is on the advisory board of Astellas, Bard, Medtronic, Apogepha, Allergan, and AMS, but these companies are not involved in the topic of this manuscript. The authors report no other conflicts of interest in this work.

\section{References}

1. De Win G, Van Bruwaene S, Allen C, De Ridder D. Design and implementation of a proficiency-based, structured endoscopy course for medical students applying for a surgical specialty. Adv Med Educ Pract. 2013;4:103-115.

2. Palter VN, Grantcharov TP. Simulation in surgical education. CMAJ. 2010;182(11):1191-1196.

3. Schout BM, Hendrikx AJ, Scheele F, Bemelmans BL, Scherpbier AJ. Validation and implementation of surgical simulators: a critical review of present, past, and future. Surg Endosc. 2010;24(3):536-546.

4. Zendejas B, Brydges R, Hamstra SJ, Cook DA. State of the evidence on simulation-based training for laparoscopic surgery: a systematic review. Ann Surg. 2013;257(4):586-593.

5. De Win G, Van Bruwaene S, De Ridder D, Miserez M. The optimal frequency of endoscopic skill labs for training and skill retention on suturing: a randomized controlled trial. J Surg Educ. 2013;70(3): 384-393.

6. Korndorffer JR, Dunne JB, Sierra R, Stefanidis D, Touchard CL, Scott DJ. Simulator training for laparoscopic suturing using performance goals translates to the operating room. J Am Coll Surg. 2005; 201(1):23-29.

7. Stefanidis D, Acker C, Heniford BT. Proficiency-based laparoscopic simulator training leads to improved operating room skill that is resistant to decay. Surg Innov. 2008;15(1):69-73.

8. Crochet P, Aggarwal R, Dubb SS, et al. Deliberate practice on a virtual reality laparoscopic simulator enhances the quality of surgical technical skills. Ann Surg. 2011;253(6):1216-1222.

9. Palter VN, Orzech N, Reznick RK, Grantcharov TP. Validation of a structured training and assessment curriculum for technical skill acquisition in minimally invasive surgery: a randomized controlled trial. Ann Surg. 2013;257(2):224-230.

10. De Win G, Van Bruwaene S, Van Calster B, De Ridder D, Miserez M. An evidence based laparoscopic simulation curriculum shortens the clinical learning curve and reduces surgical complications. Br J Surg. 2015;102(Suppl 1):19.

11. Qureshi A, Vergis A, Jimenez C, et al. MIS training in Canada: a national survey of general surgery residents. Surg Endosc. 2011;25(9):3057-3065.

12. Chiasson PM, Pace DE, Schlachta CM, Mamazza J, Poulin EC. Minimally invasive surgery training in Canada: a survey of general surgery. Surg Endosc. 2003;17(3):371-377. 
13. Schijven MP, Berlage JT, Jakimowicz JJ. Minimal-access surgery training in the Netherlands: a survey among residents-in-training for general surgery. Surg Endosc. 2004;18(12):1805-1814.

14. Navez B, Penninckx F. Laparoscopic training: results of a Belgian survey in trainees. Belgian Group for Endoscopic Surgery (BGES). Acta Chir Belg. 1999;99(2):53-58.

15. Abboudi H, Khan MS, Guru KA, et al. Learning curves for urological procedures: a systematic review. BJU Int. 2014;114(4):617-629.

16. Furriel FT, Laguna MP, Figueiredo AJ, Nunes PT, Rassweiler JJ. Training of European urology residents in laparoscopy: results of a pan-European survey. BJU Int. 2013;112(8):1223-1228.

17. Brinkman WM, Tjiam IM, Schout BM, et al. Results of the European Basic Laparoscopic Urological Skills examination. Eur Urol. 2014;65(2):490-496.

18. Preston MA, Blew BD, Breau RH, Beiko D, Oake SJ, Watterson JD. Survey of senior resident training in urologic laparoscopy, robotics and endourology surgery in Canada. Can Urol Assoc J. 2010;4(1): 42-46.

19. Blencowe NS, Parsons BA, Hollowood AD. Effects of changing work patterns on general surgical training over the last decade. Postgrad Med J. 2011;87(1034):795-799.

20. Breen KJ, Hogan AM, Mealy K. The detrimental impact of the implementation of the European working time directive (EWTD) on surgical senior house officer ( $\mathrm{SHO})$ operative experience. Ir J Med Sci. 2013;182(3):383-387.

21. Moss EL, Bredaki FE, Jones PW, Hollingworth J, Luesley DM, Chan KK. Is gynaecological surgical training a cause for concern? a questionnaire survey of trainees and trainers. BMC Med Educ. 2011;11:32.

22. Mackay S, Morgan P, Datta V, Chang A, Darzi A. Practice distribution in procedural skills training: a randomized controlled trial. Surg Endosc. 2002;16(6):957-961

23. Stefanidis D, Korndorffer JR, Sierra R, Touchard C, Dunne JB, Scott DJ. Skill retention following proficiency-based laparoscopic simulator training. Surgery. 2005;138(2):165-170.

24. Chang L, Petros J, Hess DT, Rotondi C, Babineau TJ. Integrating simulation into a surgical residency program: is voluntary participation effective? Surg Endosc. 2007;21(3):418-421.

25. van Dongen KW, van der Wal WA, Rinkes IH, Schijven MP, Broeders IA. Virtual reality training for endoscopic surgery: voluntary or obligatory? Surg Endosc. 2008;22(3):664-667.

26. De Win G, Van Bruwaene S, Aggarwal R, et al. Laparoscopy training in surgical education: the utility of incorporating a structured preclinical laparoscopy course into the traditional apprenticeship method. J Surg Educ. 2013;70(5):596-605.
27. Rogers DA, Elstein AS, Bordage G. Improving continuing medical education for surgical techniques: applying the lessons learned in the first decade of minimal access surgery. Ann Surg. 2001;233(2):159-166.

28. Tan SC, Marlow N, Field J, et al. A randomized crossover trial examining low- versus high-fidelity simulation in basic laparoscopic skills training. Surg Endosc. 2012;26(11):3207-3214.

29. Matsumoto ED, Hamstra SJ, Radomski SB, Cusimano MD. The effect of bench model fidelity on endourological skills: a randomized controlled study. J Urol. 2002;167(3):1243-1247.

30. Berg DA, Milner RE, Fisher CA, Goldberg AJ, Dempsey DT, Grewal H. A cost-effective approach to establishing a surgical skills laboratory. Surgery. 2007;142(5):712-721.

31. Korndorffer JR, Bellows CF, Tekian A, Harris IB, Downing SM. Effective home laparoscopic simulation training: a preliminary evaluation of an improved training paradigm. Am J Surg. 2012;203(1):1-7.

32. Kiely DJ, Stephanson K, Ross S. Assessing image quality of low-cost laparoscopic box trainers: options for residents training at home. Simul Healthc. 2011;6(5):292-298.

33. Bahsoun AN, Malik MM, Ahmed K, El-Hage O, Jaye P, Dasgupta P. Tablet based simulation provides a new solution to accessing laparoscopic skills training. J Surg Educ. 2013;70(1):161-163.

34. van Empel PJ, Verdam MG, Strypet M, et al. Voluntary autonomous simulator based training in minimally invasive surgery, residents' compliance and reflection. J Surg Educ. 2012;69(4):564-570.

35. Hay D, Khan MS, Van Poppel H, et al. Current status and effectiveness of mentorship programmes in urology - A systematic review. BJU Int. Epub February 27, 2014.

36. Yap SA, DeLair SM, Tanaka ST, Kurzrock EA. Current perceptions of resident training in laparoscopic nephrectomy. Urology. 2009;73(5): 1067-1071.

37. Ten Cate O. Competency-based education, entrustable professional activities, and the power of language. J Grad Med Educ. 2013;5(1): 6-7.

38. DaRosa DA, Zwischenberger JB, Meyerson SL, et al. A theory-based model for teaching and assessing residents in the operating room. J Surg Educ. 2013;70(1):24-30.

39. Beard JD, Marriott J, Purdie H, Crossley J. Assessing the surgical skills of trainees in the operating theatre: a prospective observational study of the methodology. Health Technol Assess. 2011;15(1):i-xxi, 1.

40. Peerar G, Van Humbeeck B, De Leyn P et al. The development of an electronic portfolio for postgraduate surgical training in Flanders. Acta Chir Belg. In press 2015.
Advances in Medical Education and Practice

\section{Publish your work in this journal}

Advances in Medical Education and Practice is an international, peerreviewed, open access journal that aims to present and publish research on Medical Education covering medical, dental, nursing and allied health care professional education. The journal covers undergraduate education, postgraduate training and continuing medical education

\section{Dovepress}

including emerging trends and innovative models linking education, research, and health care services. The manuscript management system is completely online and includes a very quick and fair peer-review system. Visit http://www.dovepress.com/testimonials.php to read real quotes from published authors. 